Goldschmidt 2021 Abstract

https://doi.org/10.7185/gold2021.5735

\section{USING REDOX-STAT BIOREACTORS TO ELUCIDATE MECHANISMS OF Sb MOBILIZATION IN CONTAMINATED SHOOTING RANGE SOILS
LARA CARDOSO COSTA ${ }^{1}$, ROLF KEISER ${ }^{2}$, MORITZ F. LEHMANN $^{3}$, CHRISTINE ALEWELL ${ }^{3}$ AND MARKUS LENZ $^{1}$ \\ ${ }^{1}$ Institute for Ecopreneurship, School of Life Sciences, University of Applied Sciences and Arts Northwestern Switzerland (FHNW) \\ ${ }^{2}$ ARMASUISSE Competence Center Soil \\ ${ }^{3}$ University of Basel \\ Presenting Author: lara.dacosta@fhnw.ch}

Switzerland has around 4000 shooting ranges polluted sites. Overall, an estimated 25 tons of ammunition - associated $\mathrm{Sb}$ and 200 tons of $\mathrm{Pb}$ are shot every year. Whereas $\mathrm{Pb}$ contamination can be managed by lime or phosphate addition, Sb leaching from soils into ground and surface waters represents an environmental problem. However, mechanisms leading to Sb leaching are not fully understood.

In contrast to trivalent $\mathrm{Sb}$ (antimonite), pentavalent $\mathrm{Sb}$ (antimonate) has a moderate affinity to sorb to soil $\mathrm{Fe}$ and $\mathrm{Mn}$ hydr(oxides). During water logging, soils can become anoxic, favoring reductive dissolution of $\mathrm{Fe}$ and $\mathrm{Mn}$ phases, mobilizing sorbed antimonate. However, moderately reducing conditions are also conducive to the microbial reduction of antimonate to antimonite, aiding the adsorption-driven sequestration of $\mathrm{Sb}$. The interplay and balance between multiple reductive reactions thus ultimately controls $\mathrm{Sb}$ mobility [1]. Since several redox reactions can occur simultaneously it is difficult to assess their individual contribution to $\mathrm{Sb}$ fate.

Continuous-stirred-tank bioreactors were operated as "redoxstats" to elucidate individually the contribution of reductive processes in shooting range soils. [2] More specifically, the redox potential was set to $\geq 450 \mathrm{mV}$ which made $\mathrm{Fe}$ and $\mathrm{Sb}$ reduction not thermodynamically favoured and thus allowed us to quantify the impact of $\mathrm{Mn}$ reduction on $\mathrm{Sb}$ mobilization. $\mathrm{Sb}$ speciation was accessed by LC - ICP - MS, whereas total dissolved metal ( $\mathrm{Sb}, \mathrm{Pb}, \mathrm{Mn}, \mathrm{Fe})$ concentrations were measured by ICP-MS. Dissolved organic matter (DOM) was determined by TOC analysis. Ultimately, $\mathrm{Sb}$ and $\mathrm{Pb}$ mobilization were correlated to dissolved Mn, Fe and DOM. A sequential extraction of soil was performed at the beginning and upon termination of the experiment to assess metal bioavailability. Preliminary results underscore clear links between $\mathrm{Sb}$ and $\mathrm{Mn}$ hydr(oxide) reductive dissolution, while suggesting a minor/subordinated role of Fe.

[1] K. Hockmann, M. Lenz, S. Tandy, M. Nachtegaal, M. Janousch, and R. Schulin, "Release of antimony from contaminated soil induced by redox changes," J. Hazard. Mater., 2014, doi: 10.1016/j.jhazmat.2014.04.065.
[2] L. Rajpert, A. Schäffer, and M. Lenz, "Redox-stat bioreactors for elucidating mobilisation mechanisms of trace elements: an example of As-contaminated mining soils," Appl. Microbiol. Biotechnol., 2018, doi: 10.1007/s00253-018-9165-4. 